ISSN (Print) : : 1412-7601

ISSN (Online) : 2654-8712

Volume 5, No.1 Maret 2019

EKONOBIS

http://www.ekonobis.unram.ac.id

\title{
Analisis Tingkat Pendidikan Anak Tenga Kerja Wanita Yang Bermigrasi Ke Luar Negeri Di Kabupaten Lombok Timur
}

\section{Luluk Fadliyanti, Muaidy Yasin, Himawan Sutanto}

Universitas Mataram

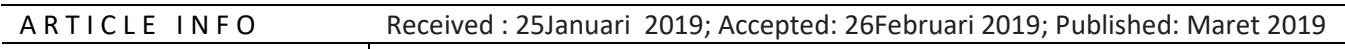

Keywords :

Education, migrant and non migrant workers, OLS
ABSTRACT :This study aims to analyze the factors that affect the level of education of female child labor migrants abroad. This study uses quantitative research with a type of case study research. The data used are primary data collected through interviews of questionnaires and secondary data from Badan Pusat Statistik Nusa Tenggara Barat, Badan Pusat Statistik Kabupaten Lombok Timur dan Dinas Ketenagakerjaan kabupaten Lombok Timur. The sampling method used is the Purposive Sampling method, which is a deliberate sampling technique. And the analysis tool used is the analysis of Multiple Regression with the Ordinary Least Square-Double Log model. The results showed that the education level of children, the age of children and household needs had a significant effect on the level of education of children. While the sex of the child does not have a significant effect on the level of education. And children from migrant workers or non-migrants have no significant effect on children's education level.

Kata Kunci :

Pendidikan, TKW Migran , OLS.

ABSTRAK: Penelitian ini bertujuan untuk menganalisis faktor-faktor yang mempengaruhi tingkat pendidikan anak tenaga kerja wanita yang bermigrasi ke luar negeri. Penelitian ini menggunakan penelitian kuantitatif dengan jenis penelitian studi kasus. Data yang digunakan adalah data primer yang dikumpulkan melalui wawancara dengan bantuan kuisioner dan data sekunder dari Badan Pusat Statistik Nusa Tenggara Barat, Badan Pusat Statistik Kabupaten Lombok Timur dan Dinas Ketenagakerjaan Kabupaten Lombok Timur. Metode pengambilan sampel yang digunakan adalah metode Purposive Sampling yaitu teknik pengambilan sampel yang sengaja. Dan alat analisis yang digunakan adalah analisis Regresi Berganda dengan model Ordinary Least Square-Double Log. Hasil penelitian menunjukkan bahwa tingkat pendidikan anak, usia anak dan kebutuhan rumah tangga berpengaruh signifikan terhadap tingkat pendidikan anak. Sedangkan jenis kelamin anak tidak berpengaruh signifikan terhadap tingkat pendidikan. Dan anak berasal dari TKW Migran atau Non-Migran tidak berpengaruh signifikan terhadap tingkat pendidikan anak.

Corresponding Author:

Alamat : Program Studi Ekonomi Pembangunan, Fakultas Ekonomi dan Bisnis, Universitas Mataram, Jln. Majapahit No. 62 Mataram.

e-mail: lulukfadliyanti@gmail.com 


\section{PENDAHULUAN}

\section{Latar Belakang}

Migrasi Indonesia telah terjadi selama ratusan tahun lalu, tetapi meningkat secara tajam sejak tahun 1970 hingga sekarang. Tenaga kerja dari Indonesia yang bekerja di luar negeri atau yang dikenal dengan sebutan Tenaga Kerja Indonesia (TKI) meninggalkan rumah mereka untuk beberapa alasan termasuk kurangnya peluang kerja, kemiskinan, dan perbedaan pendapatan di Indonesia dengan negara tujuan. Secara resmi kepengurusan penempatan TKI oleh pemerintah dan dimulai pada tahun 1969, yang pada saat itu ditangani oleh Departemen Tenaga Kerja. Adanya Peraturan Pemerintah No.4 tahun 1970, program penempatan Angkatan Kerja Antar Daerah (AKAD) dan Antar Kerja Antar Negara (AKAN) dibuat oleh pemerintah untuk memudahkan jalan bagi keterlibatan sektor swasta dalam industri perekrutan dan penempatan tenaga kerja.

Perempuan memainkan peranan penting dalam migrasi tenaga kerja internasional dan sekarang mencapai 49,6 persen dari jumlah keseluruhan tenaga kerja secara global (IOM, 2008).Di negaranegara berkembang, di mana kebanyakan tenaga kerja mereka merupakan pekerja tidak tetap, proporsi tenaga kerja perempuan meningkat secara drastis dari tahun 1970 hingga tahun-tahun berikutnya.Negara-negara tujuan utama tenaga kerja wanita (TKW) dari Asia adalah wilayah Asia Timur, Asia Barat, Asia Tenggara dan Asia Pasifik. Di beberapa negara bahkan jumlah TKW mencapai 70 persen dari keseluruhan jumlah tenaga kerja.

Di Indonesia pada tahun 2016, sebanyak lima daerah yang merupakan sumber tenaga kerja Indonesia (TKI) terbesar, yaitu Jawa Barat sebanyak 31.027 orang, Jawa Tengah sebanyak 29.394 orang, Jawa Timur 27.381 orang, Nusa Tenggara Barat 23.859 orang, Sumatra Utara 11.952 orang. Berdasarkan Kabupaten/Kota yaitu tertinggi Kabupaten Lombok Timur 10.621 orang, Indramayu 10.390 orang, Lombok Tengah 6.917 orang, Cirebon 6.408 orang, dan Cilacap 5.448 orang. Dari jumlah tenaga kerja Indonesia, jumlah tenaga kerja wanita (TKW) sebesar $62 \%$ dan laki-laki sebesar $38 \%$ dari jumlah TKI secara keseluruhan.Dari 26 negara-negara yang paling banyak terdapat penempatan TKI, tercatat 10 negara terbesar untuk penempatan TKI yaitu Malaysia, Taiwan, Hong Kong, Singapore, Saudi Arabia, Brunei Darussalam, Korea Selatan, United 
Arab Emirates, Oman, dan Qatar (Puslitfo, BNP2TKI, 2017).

Provinsi Nusa Tenggara Barat merupakan provinsi dengan jumlah pengiriman TKI terbesar kedua di Indonesia setelah Provinsi Jawa Barat, dengan jumlah remittance yang diterima pada tahun tersebut sebesar 1,7 Triliun Rupiah (Puslitfo BNP2TKI, 2017). Jika diasumsikan bahwa setiap TKI mengirimkan uang sejumlah 20 Juta rupiah per tahun, maka jumlah total kiriman uang para TKI tersebut mencapai sekitar 1 Triliun Rupiah setiap tahunnya. Jumlah kiriman uang tersebut ke Provinsi NTB akan jauh lebih besar jika dihitung pula kiriman uang yang dilakukan melalui jalur informal, termasuk kiriman uang TKI ilegal. Oleh sebab itu tidak diragukan lagi bahwa migrasi internasional dalam pengiriman TKI telah menjadi solusi riil bagi kemiskinan di Provinsi NTB.

Kabupaten Lombok Timur dengan Ibu Kota Selong merupakan salah satu dari sepuluh kabupaten/kota di Provinsi Nusa Tenggara Barat.Dimana kabupaten ini pada tahun 2016 merupakan kabupaten pengirim tenaga kerja wanita tertinggi di Indonesia (Puslitfo BNP2TKI, 2017).Keterlibatan perempuan dalam ekonomi merupakan fenomena penting dalam era globalisasi.Perempuan di pedesaan kabupaten ini terutama kalangan menengah ke bawah hampir seluruhnya terlibat dalam kegiatan ekonomi. Mereka berupaya memperbaiki ekonomi keluarga hingga meninggalkan desa dan mencari alternatif pekerjaan. Kemampuan wanita dalam memberikan kontribusi secara ekonomi terhadap pendapatan keluarga/rumah tangganya, akan meningkatkan status sosial keluarganya dalam masyarakat, namun keterbatasan keterampilan dan kemampuan dalam menguasai teknologi menjadi penghambat dalam mencari pekerjaan. Selain itu, semakin meningkatnya globalisasi menuntut persaingan yang lebih ketat lagi, warga masyarakat dengan kemampuan yang serba terbatas akan terpinggirkan dari dunia kerja.

Menjadi tenaga kerja wanita migran ke luar negeri tentunya membawa dampak terhadap kehidupan keluarga dan daerah asal migran dampak yang muncul tidak hanya berkaitan dengan aspek ekonomi, akan tetapi mencakup aspekaspek lain termasuk kehidupan sosial. Dari sisi ekonomi mobiltas tersebut cenderung mendapatkan dampak positif, antara lain terpenuhinya kebutuhan rumah tangga migran serta lebih bergeraknya perekonomian daeran akibat dari 
remittance yang dikirimkan. Walaupun dampak negatif sering terjadi di dalam rumah tangga tenaga kerja migran, namun hal tersebut tidak menyurutkan keinginan mereka untuk melakukan migrasi ke luar negeri, karena selain dorongan ekonomi rumah tangga juga hal tersebut disebabkan karena mereka melihat para tenaga kerja yang telah kembali ke daerah asal mampu memperbaiki kehidupan ekonominya. Dampak positif yang secara langsung dapat dirasakan adalah tercapainya kesejahteraan anggota keluarga, dalam artian terpenuhi kebutuhan rumah tangga yang mencakup kebutuhan dasar dan kebutuhan lainnya untuk terlibat secara penuh dengan kehidupan sosial. Seperti kebutuhan akan makanan, pendidikan dan kesehatan anak. Kesejahteraan keluarga yang ditinggalkan tenaga kerja migran meningkat secara signifikan dengan remittance yang di transfer (Quartey, 2006).

Bryant (2005) menyebutkan bahwa pertumbuhan migrasi international di negara-negara selatan dan timur Asia berpengaruh secara signifikan terhadap anak-anak, sekitar 3 - 6 juta anak dari Filipina yang telah ditinggalkan oleh orangtuanya bermigrasi ke luar negeri, di Indonesia sekitar 1 juta anak yang juga ditinggalkan oleh orangtuanya bermigrasi ke luar negeri dan 0,5 juta anak dari Thailand yang juga mengalami hal yang sama. Hal tersebut pada akhirnya akan memberikan dampak positif dan negatif bagi kelangsungan hidup anak-anak tersebut. Bagi migrasi internasional yang dilakukan oleh tenaga kerja wanita yang telah menikah, pada umumnya anak-anak yang ditinggalkan oleh tenaga kerja wanita tersebut hidup bersama ayah dan nenek mereka. Sementara uang yang dikirim oleh tenaga kerja wanita tersebut ke daerah asalnya belum tentu dapat dimanfaatkan secara langsung untuk memenuhi kebutuhan anak. Bahkan sebagian besar remittance yang dikirim digunakan bukan untuk kebutuhan anak.

Departemen Gizi Masyarakat Fakultas Ekologi Manusia (FEMA) Institut Pertanian Bogor menganalisis masalah pendidikan dan kesehatan anak di kabupaten Sukabumi Jawa Barat dengan menggunakan 300 sampel tenaga kerja wanita yang mempunyai anak, hasilnya menunjukkan bahwa sekitar 40 persen anak yang ditinggalkan oleh ibunya yang bekerja sebagai tenaga kerja wanita di luar negeri mempunyai perkembangan kecerdasan dan sosialitas yang rendah, sementara 14 persen balita yang ditinggalkan para tenaga kerja wanita 
mengalami kekurangan gizi dan 2 persen mengalami gizi buruk. Karena desakan ekonomi keluarga, dampak positif dan negatif yang timbul dari pengiriman tenaga kerja wanita yang sudah menikah tetap saja menjadi motif utama untuk tenaga kerja waita tersebut bermigrasi ke luar negeri dengan meninggalkan anakanak mereka diasuh oleh keluarga. Berdasarkan uraian latar belakang di atas, maka rumusan masalah dalam penelitian ini adalah apakah karakteristik individu dan karakteristik rumah tangga mempunyai pengaruh terhadap tingkat pendidikan anak dari tenaga kerja wanita yang bermigrasi ke luar negeri?

\section{Tujuan Penelitian}

Untuk mengetahui pengaruh karakteristik individu dan karakteristik rumah tangga terhadap tingkat pendidikan anak dari tenaga kerja wanita yang bermigrasi ke luar negeri.

\section{Batasan Penelitian}

Penelitian ini mempunyai batasan dalam permasalahan yang diambil, yaitu sebagai berikut:

1. Penelitian ini difokuskan kepada tenaga kerja wanita yang sudah menikah atau janda.

2. Tenaga kerja wanita yang dimaksud di dalam penelitian ini adalah tenaga kerja wanita yang bermigrasi ke Negara Malaysia, Saudi Arabia, dan Timur Tengah.

\section{TINJAUAN PUSTAKA}

Migrasi didefinisikan sebagai perpindahan penduduk dengan tujuan untuk menetap dari suatu tempat ke tempat yang lain melampaui batas politik/negara bagian suatu negara. Perpindahan penduduk antar daerah atau suatu negara tidak bisa lepas dari kondisi sosial dan ekonomi suatu negara tersebut.Para pakar ilmu sosial melihat migrasi (mobilitas penduduk) merupakan jawaban atas suatu pertanyaan mengenai mengapa penduduk memutuskan untuk pindah atau menetap pada suatu daerah. Proses di dalam mempertahankan hidup harus dilihat dalam arti yang luas dari sisi ekonomi, sosial, politik maupun budaya. Keputusan migrasi dilakukan karena ada penyebabnya yaitu salah satunya keinginan individu/keluarga untuk memperbaiki kondisi ekonomi mereka.

Teori New Economic Labour Migration (NELM) yang memandang migrasi merupakan keputusan keluarga dalam rangka meningkatkan perekonomian keluarga. Ketika wanita mengambil alih tanggung jawab di dalam menafkahi keluarga, maka secara langsung alih tanggung jawab untuk 
mengasuh dan mendidik anak berpindah tangan kepada suami atau keluarga. Tentunya pola pengasuhan anak tidak sama dengan pola asuh ibu dalam mendidik dan mengasuh anak. Tetapi dengan adanya pendapatan yang diterima dari migrasi, maka pendapatan tersebut diharapkan dapat memenuhi semua kebutuhan anak baik dalam kesehatan dan pendidikan anak. Cortes (2007) menyebutkan bahwa NELM mempunyai fokus pada rumah tangga, dimana dampak dari migrasi yang khususnya pada pendapatan yang diterima. Dimana konsekuensi dari ketidakhadiran ibu dapat digantikan dengan pendapatan yang dikirim kepada anak tersebut.

Teori gender yaitu teori nurture menyebutkan bahwa adanya perbedaan perempuan dan laki-laki pada hakikatnya adalah hasil konstruksi sosial budaya sehingga menghasilkan peran dan tugas yang berbeda. Sedangkan menurut teori nature, adanya perbedaan perempuan dan laki-laki adalah karena kodrat yang menyebabkan perbedaan biologis yang memberikan implikasi bahwa kedua jenis tersebut memiliki peran dan tugas yang berbeda. Dan teori Equilibrium dikenal dengan adanya keseimbangan menekankan pada konsep kemitraan dan keharmonisan dalam bekerjasama serta hubungan antara perempuan dan laki laki. Pada hakikatnya, untuk mengembangkan dan mematangkan berbagai potensi yang ada pada diri perempuan dapat memanfaatkan hak dan kesempatan yang sama dengan laki-laki sebagai sumber daya pembangunan. Namun hingga kini masih dirasakan ada kesenjangan gender atau bias gender dalam berbagai sektor pembangunan sehingga posisi dan kondisi kaum perempuan belum setara dengan kaum laki-laki. Konsep ini penting dipahami untuk membahas masalah kaum wanita di dalam menganalisis dalam memahami masalah-masalah ketidakadilan yang menimpa kaum wanita.

Becker (1965) dalam teori fertilitas menyebutkan bahwa anak dari sisi ekonomi pada dasarnya dapat di anggap sebagai barang konsumsi yang memberikan kepuasan tertentu bagi orang tua.Bagi para orang tua, anak merupakan sumber pendapatan dan kepuasan. Selain itu peningkatan waktu pada pengeluaran untuk anak bukan berarti bahwa biaya anak akan meningkat ketika kualitas anak juga meningkat.

Resosudarmo, et al. (2009) menganalisis mengenai sosial-ekonomi dan kesehatan pada migran dari desa ke kota di Indonesia, dengan 
membandingkan pencapaian sosialekonomi dan status kesehatan migran dan non migran di kota yang sama, menggunakan model Probit dengan variabel-variabel berat badan anggota rumah tangga baik yang dewasa maupun anak-anak, persentase anak-anak yang terlambat masuk sekolah, rata-rata jangka waktu sekolah anak. Hasilnya menunjukkan bahwa pendapatan rumah tangga migran lebih tinggi daripada pendapatan non-migran. Status kesehatan migran dan anak-anak migran sama dengan status kesehatan non-migran, begitu pula dengan pendidikan anak-anak, justru partisipasi di sekolah pada anakanak migran lebih lebih baik dari partisipasi di sekolah pada anak-anak non migran. Hal tersebut menunjukkan bahwa migrasi meningkatkan kondisi sosialekonomi mereka

Lu dan Theiman (2007) menganalisa pengaruh dari remittance yang dikirim oleh tenaga kerja kulit hitam di Africa Selatan terhadap sekolah anak. Dengan menggunakan cross-sectional data dari tahun 1993 - 1994 gabungan survei rumah tangga dan data panel dari tahun 2002 dan 2003 survei tenaga kerja Afrika Selatan, hasilnya bahwa tenaga kerja migran dan kemungkinan remittance yang di kirim ke rumah adalah lebih merata antara kulit hitam dengan grup rasial lainnya, sedangkan dampak dari migrasi dan remittance pada pendidikan anak kulit hitam adalah pada dasarnya penerimaan remittance kemungkinan akan meningkat jika melalui 3 (tiga) cara, yaitu meningkatkan pengeluaran rumah tangga untuk pendidikan, pengurangan tenaga kerja anak, dan kelonggaran dari pengaruh negatif ketidakhadiran orang tua untuk bermigrasi keluar.

Bryant (2005) mengenai Children of International Migration in Indonesia, Thailand and the Philippnes untuk melihat 3 (tiga) grup anak-anak yang dipengaruhi oleh migrasi Internasional, yaitu anakanak yang ditinggalkan oleh orangtuanya bermigrasi dari Philiphina, Indonesia dan Thailand, anak-anak dari Thailand yang berada di Jepang, dan anak-anak yang dibawa serta orangtua mereka bermigrasi ke luar negeri. Hasilnya untuk anak-anak yang ditinggalkan oleh orangtuanya bermigrasi adalah menunjukkan bahwa orangtua migran dapat meningkatkan kondisi ekonomi keluarga dari hasil remittance yang kemungkinan dapat digunakan untuk biaya pendidikan dan kesehatan anak, biaya sosial yang terjadi dapat dikurangi dengan keterlibatan anggota keluarga yang lain. McKenzie (2006) menyebutkan bahwa balita 
menjadi kekurangan ASI atau tidak mendapatkan imunisasi secara lengkap akibat ditinggalkan oleh ibu mereka yang menjadi tenaga kerja migran.

Quisumbing dan Maluccio (2000), menggunakan data dari Bangladesh, Ethiopia, Indonesia, dan Afrika Selatan, menyimpulkan bahwa efek yang paling konsisten di negara-negara tersebut adalah persentase peningkatan sumber daya dikendalikan oleh wanita pada saat pernikahan adalah peningkatan jumlah pengeluaran untuk pendidikan. Temuan ini berlaku untuk semua negara kecuali untuk Ethiopia. Penelitian serupa di pedesaan Bangladesh menemukan bahwa peningkatan aset perempuan memiliki efek positif pada pengeluaran untuk pakaian anak-anak dan pendidikan (Hallman, 2000; Quisumbing dan de la Brière, 2000). Perilaku ini oleh perempuan mungkin sangat rasional, karena perempuan sering menikah pada usia dini dibandingkan laki-laki dan juga memiliki rata-rata harapan hidup yang lebih lama dari suami mereka. Akibatnya, mereka memilih untuk berinvestasi dalam pendidikan anak-anak mereka, karena mereka bergantung pada mereka untuk dukungan hari tuanya dibandingkan lakilaki (Quisumbing dan Maluccio 2000).
Loken (2007) yang menganalisis tentang hubungan pendapatan keluarga dan keberhasilan pendidikan anak, melakukan penelitian untuk mengamati sebab-akibat dari hubungan tersebut. Data yang digunakan adalah penduduk Norwegia pada periode 1968 dan 1973 dengan mengukur pendapatan tetap keluarga dari anak yang berusia 0 - 20 tahun untuk melihat pengaruh jangka panjang dari pendapatan keluarga terhadap hasil pendidikan anak. The Norwegian oil shock pada tahun 1970 dan 1980 digunakan sebagai instrumen penelitian ketika secara tidak langsung meningkatkan pendapatan di beberapa wilayah. Perbedaan pendapatan digunakan untuk mengestimasi sebabakibat pengaruh dari pendapatan keluarga pada keberhasilan pendidikan anak. Dan hasilnya menunjukkan bahwa tidak ada hubungan sebab-akibat antara pendapatan keluarga dengan keberhasilan pendidikan anak. Whitehead dan Hashim (2005) dalam penelitiannya mengenai anak-anak dan migrasi menyebutkan sangat sulit untuk mengestimasi dampak migrasi orangtua terhadap kesehatan, mortalitas dan pendidikan anak.

$$
\text { Acosta (2007) melakukan }
$$
penelitian mengenai dampak remittance terhadap kemiskinan, pendidikan dan 
|26 LufukFadliyanti, Muaidy Yasin, Himawan Sutanto/Analisis Tingkat Pendidikan....

kesehatan pada sebelas negara Amerika Latin dengan menggunakan survei anggota keluarga dan mencoba menghitung satu dari seluruh biaya yang dikumpulkan dengan migrasi. Hasilnya ditemukan bahwa dengan adanya remittence dapat mengurangi tingkat kemiskinan di negara yang menerima remittance, hal tersebut juga berdampak pada GDP negara tersebut. Selain itu remittance mempunya dampak positif terhadap pendidikan dan kesehatan keluarga.

Di Indonesia sendiri saat ini masih pada taraf sosialisasi mengenai kesetaraan gender dan memberikan preferensi untuk pengembangan kariernya di pasar kerja. Dengan adanya migrasi mampu mengubah tatanan sosialkultural masyarakat sebelumnya, terutama yang berkaitan dengan peran gender dan sekaligus mengubah penampilan dan gaya hidup wanita desa. Ketika keputusan wanita untuk bermigrasi di ambil karena dorongan kemiskinan, pada saat itu juga telah terjadi perubahan peran gender dalam rumah tangga di mana wanita memberikan kontribusi ekonomi yang dominan dan tidak jarang menjadi pencari nafkah utama.Dan juga konstruksi sosial kultural mengenai tempat perempuan yang seharusnya di lingkup domestik telah mengalami perubahan.Semakin meningkatnya jumlah perempuan yang menjadi tenaga kerja migran dan menjadi pencari nafkah utama bagi kehidupan rumah tangga, dengan sendirinya memberikan arti bahwa pekerjaan perempuan tidak lagi sebatas ruang domestik.Perempuan telah menjadi pelaku aktif di ruang publik.Dan implikasi lanjutan dari aktivitas perempuan di ruang publik yaitu meningkatnya kesadaran perempuan terhadap eksistensi diri dan bersamaan dengan itu kemampuan mengartikulasi diri juga meningkat, dibandingkan dengan perempuan yang tidak migrasi.

\section{Hipotesis}

Diduga karakteristik individu dan karakteristik rumah tangga mempunyai pengaruh terhadap tingkat pendidikan anak dari tenaga kerja wanita yang bermigrasi ke luar negeri.

\section{METODELOGI PENELITIAN}

Penelitian ini menggunakan penelitian kuantitatif, dengan jenis penelitian studi kasus yang bertujuan untuk memberikan gambaran secara mendetail mengenai latar belakang, sifat-sifat serta karakterkarakter yang khas dari kasus, ataupun status dari individu, yang kemudian dari sifat-sifat yang khas di atas akan dijadikan 
sesuatu yang bersifat umum (Nazir, 2005). Lokasi peneltian ini dilakukan di kabupaten Lombok Timur dengan mengambil 5 kecamatan dari 20 kecamatan yang ada di kabupaten tersebut.Adapun kecamatan yang dimaksud meliputi kecamatan Terara, Sakra Barat, Aikmel, Keruak, Pringgabaya. Pertimbangan dalam menentukan lokasi penelitian adalah disebabkan karena ke lima kecamatan yang menjadi lokasi penelitian merupakan kecamatan yang mempunyai jumlah tenaga kerja wanita yang terbesar di kabupaten Lombok Timur.Metode penelitian yang digunakan adalah data primer dan data sekunder

Dari keseluruhan populasi, jumlah sampel yang diambil adalah sebanyak 50 orang, yaitu 25 TKW migarn dan 25 TKW non migran. Kemudian berdasarkan 5 (lima) kecamatan yang menjadi lokasi penelitian ditentukan desa-desa tempat pengambilan sampel. Sampel yang diambil pada tiap desa tergantung pada jumlah tenaga kerja wanita yang ada.Metode pengambilan sampel yang digunakan untuk penelitian ini adalah metode Purposive Sampling yaitu tekhnik pengambilan sampel yang sengaja, sampel ditentukan pada 5 kecamatan di kabupaten Lombok Timur, yaitu Terara, Aikmel, Sakra Barat, Pringgabaya dan
Keruak. Masing-masing kecamatan di ambil sampel sebanyak 2 desa dengan pertimbangan dapat mewakili responden dari desa-desa yang ada di kabupaten tersebut.Selain itu juga dengan pertimbangan efisiensi waktu dan biaya serta tenaga, agar dapat lebih memudahkan pelaksanaan penelitian.Untuk menganalisis tingkat pendidikan dan kesehatan anak menggunakan analisis regresi berganda dengan model Ordinary Least Square (OLS) - Double Log dengan mengikuti variabel-variabel dan salah satu dari alat analisis yang digunakan oleh Resosudarmo, et al. (2009), dengan pengukuran peubah sebagai berikut :

$\operatorname{LogTP}=b_{0}+b_{1} \log K I 1+b_{2} K I 2+$ $b_{3} \log K R T+b_{4} T K+\epsilon$

Definisi variabel-variabel tingkat pendidikan dan kesehatan anak tenaga kerja wanita migran dan non migran adalah sebagai berikut:

1. TP adalah tingkat pendidikan anak terkecil usia sekolah, yaitu tingkat pendidikan anak tenaga kerja migran dan non-migran yang dilihat dari jenjang pendidikan yang sedang di tempuh anak, yaitu (1) SD, (2) SMP, (3) SMA dan (4) Perguruan Tinggi.

2. KI1 adalah karakteristik individu, yaitu usia anak tenaga kerja wanita migran 
|28 Luluk Fadliyanti, Muaidy Yasin, Himawan Sutanto/Analisis Tingkat Pendidikan....

dan non-migran, dimana usia anak tenaga kerja migran dan non migran yang terkecil yang sudah memasuki sekolah minimal Sekolah Dasar.

3. KI2 adalah karakteristik individu, yaitu jenis kelamin anak tenaga kerja wanita migran dan non-migran. (jika 1: lakilaki ; 0: perempuan).

4. KRT adalah karakteristik rumah tangga, yaitu jumlah pengeluaran rumah tangga meliputi kebutuhan pokok makanan dan non makanan termasuk pengeluaran pendidikan dan kesehatan.

5. TK adalah anak dari tenaga kerja wanita, yaitu anak yang berasal dari tenaga kerja wanita migran dan nonmigran, (jika 1: migran dan jika 0: nonmigran).
Hasil Analisis OLS (Double Log)Tingkat

\section{Pendidikan Anak}

Tabel 1.Tenaga Kerja Wanita Migran dan Non Migran

\begin{tabular}{|l|c|c|c|c|}
\hline \multicolumn{1}{|c|}{ Variabel } & Coefficient & t-Statistik & Probabilitas & Keterangan \\
\hline \multicolumn{1}{|c|}{ C } & -2.057156 & -2.367834 & 0.0227 & $(-)$ signifikan \\
\hline Log (KI1) & 0.989595 & 7.837736 & 0.0000 & $(+)$ signifikan \\
\hline KI2 & 0.119769 & 1.450420 & 1.1545 & $\begin{array}{c}(+) \text { tidak } \\
\text { signifikan }\end{array}$ \\
\hline Log(TKRT) & -0.009037 & -0.141624 & 0.8881 & $\begin{array}{c}(-) \text { tidak } \\
\text { signifikan }\end{array}$ \\
\hline TK & 0.026645 & 0.288986 & 0.7740 & $\begin{array}{c}(+) \text { tidak } \\
\text { signifikan }\end{array}$ \\
\hline $\begin{array}{l}\text { R-Squared } \\
\text { Prob. } \\
\text { F-Stat. }\end{array}$ & $: 0.653381$ & & & \\
\hline
\end{tabular}

Sumber: Output Eviews 7, diolah

Keterangan: * Signifikan pada tingkat 5\%

$\operatorname{LogTP}=-2.057156+0.989595 \log (\mathrm{KI} 1)+$

0.119769KI2-0.009037Log(TKRT)+

$0.026645 T K+\varepsilon$

Pengaruh Usia Anak Terhadap Tingkat

Pendidikan Anak Tenaga Kerja Wanita

Yang Bermigrasi Ke Luar Negeri
Koefisien regresi untuk variabel usia anak adalah sebesar 0.989595 dengan probabilitas sebesar 0.0000 . Dari nilai

yang diperoleh menunjukkan bahwa variabel usia anak berpengaruh signifikan terhadap tingkat pendidikan anak. Artinya bahwa setiap peningkatan usia anak sebanyak 1 tahun maka akan 
meningkatkan tingkat pendidikan anak tenaga kerja wanita yang bermigrasi ke luar negeri sebesar 9.76 kali yang merupakan hasil dari (anti log 0.989595). Hasil penelitian ini tidak sesuai dengan penelitian yang dilakukan oleh Whitehead dan Hashim (2005) yang dalam penelitiannya mengenai anak-anak dan migrasi menyebutkan sangat sulit untuk mengestimasi dampak migrasi orang tua terhadap kesehatan, mortalitas dan pendidikan anak.

Pengaruh Jenis Kelamin Terhadap Tingkat Pendidikan Anak Tenaga Kerja Wanita Yang Bermigrasi Ke Luar Negeri

Koefisien regresi untuk variabel jenis kelamin anak adalah sebesar 0.119769 dengan probabilitas sebesar 0.1545. Dari nilai yang diperoleh menunjukkan bahwa variabel jenis kelamin anak tidak berpengaruh signifikan terhadap tingkat pendidikan anak. Hal ini bermakna bahwa apabila variabel Jenis Kelamin Anak adalah Laki-Laki dengan KI2=1 maka nilai keterpengaruhan akan lebih besar, dengan kata lain anak yang berjenis kelamin laki-laki memiliki tingkat pendidikan yang lebih baik bila dibandingkan dengan anak perempuan dimana $\mathrm{KI} 2=0$.

Hasil penelitian ini tidak sesuai dengan penelitian yang telah dilakukan oleh Gao, et.al. (2010). Hasil penelitian tersebut menunjukkan bahwa remaja lakilaki yang ditinggalkan oleh orang tuanya mempunyai resiko yang lebih tinggi untuk tidak makan pagi mempunyai aktivitas fisik yang lebih tinggi penggemar internet, merokok, ide untuk bunuh diri dan memiliki kecenderungan obesitas. Sedangkan untuk anak remaja perempuan mempunyai kecenderungan untuk menyukai minuman manis yang berlebih, lebih banyak menonton TV, merokok, mengkonsumsi alcohol dan pesta minuman. Mereka juga merasa tidak bahagia, memikirkan rencana bunuh diri dan mempunyai keinginan pergi dari rumah. Artinya bahwa baik anak laki-laki maupun perempuan mempunyai resiko yang sama untuk tidak sekolah, jika orang tua mereka tidak mendampingi mereka.

Pengaruh Pengeluaran Rumah Tangga Terhadap Tingkat Pendidikan Anak Tenaga Kerja Wanita Yang Bermigrasi Ke Luar Negeri

Koefisien regresi variabel Jumlah Pengeluaran Rumah Tangga (TKRT) memiliki nilai sebesar - 0,009037 atau nilai variabel TKRT sebesar 0,979407 (anti log dari -0,009037) dan arah hubungan regresi bertanda negatif, yang bermakna bahwa Jumlah Pengeluaran Rumah Tangga memiliki pengaruh yang negatif 
|30 Luluk Fadliyanti, Muaidy Yasin, Himawan Sutanto/Analisis Tingkat Pendidikan....

terhadap Tingkat Pendidikan Anak TKW

Migran maupun Non-Migran. Jika

Pengeluaran Rumah Tangga mengalami

peningkatan maka akan menurunkan

Tingkat Pendidikan Anak, begitu pula

sebaliknya apabila Pengeluaran Rumah

Tangga mengalami penurunan maka akan

meningkatkan Tingkat Pendidikan Anak.

Tetapi hal ini tidak sesuai dengan pendapat Becker (1960) dalam teori fertilitas menyebutkan bahwa anak dari sisi ekonomi pada dasarnya dapat di anggap sebagai barang konsumsi yang memberikan kepuasan tertentu bagi orang tua.Bagi para orang tua, anak merupakan sumber pendapatan dan kepuasan. Selain itu peningkatan pada pengeluaran untuk anak bukan berarti bahwa biaya anak akan meningkat ketika kualitas anak juga meningkat.

\section{Pengaruh Anak Berasal Dari TKW Migran} atau Non-Migran Terhadap Tingkat Pendidikan Anak Tenaga Kerja Wanita Yang Bermigrasi Ke Luar Negeri

Koefisien regresi variabel Anak Berasal dari TKW Migran atau Non Migran (TK) memiliki nilai sebesar 0,026644 dengan nilai probabilitas sebesar 0.8881 . Dan arah hubungan regresi bertanda positif yang bemakna variabel ini berpengaruh positif terhadap Tingkat Pendidikan Anak. Bila dilihat dari Asal Anak dimana TK=1 merupakan anak dari TKW Migran dan $\mathrm{TK}=0$ berasal dari anak TKW Non-Migran. Maka pengaruhnya yang lebih besar adalah dari Anak TKW Migran bila dibandingkan dengan anak TKW NonMigran. Hal tersebut dapat dilihat dari nilai koefisien regresi $T K=1$ yang lebih besar daripada $\mathrm{TK}=0$.

Hasil penelitian ini sesuai dengan penelitian yang dilakukan oleh Resosudarmo, et al. (2009) yang dimana hasil penelitiannya menunjukkan bahwa pendapatan rumah tangga migran lebih tingga daripada pendapatan non-migran. Status pendidikan anak-anak, justru partisipasi di sekolah pada anak-anak migran lebih baik daripada partisipasi di sekolah pada anak-anak non-migran. Serta penelitian yang dilakukan oleh Quinsumbing dan De la Briere (2000). Hasil penelitiannya menunjukkan bahwa perilaku perempuan sangat rasional, karena perempuan sering menikah pada usia dini dibandingkan laki-laki dan juga memiliki rata-rata hidup yang lebih lama dari suami. Akibatnya mereka lebih memilih untuk berinvestasi dalam pendidikan anak-anak mereka bergantung pada mereka untuk dukungan hari tuanya dibandingkan laki-laki.

Hasil Uji Asumsi Klasik

\section{Uji Autokorelasi}


Uji autokorelasi bertujuan untuk Berdasarkan tabel di atas dapat menguji apakah dalam suatu model diinterpretasikan bahwa dimana sebuah regresi linear ada korelasi antara model dinyatakan mengandung kesalahan pengganggu pada periode $\mathrm{t}$ heteroskedastisitas apabila probabilitas $\mathrm{F}$ dengan kesalahan pengganggu $\mathrm{t}-1$ hitung lebih kecil dari taraf alpha 5\% dan (sebelumnya).Untuk mendeteksi sebaliknya dinyatakan tidak mengandung autokorelasi dapat dilakukan melalui metode Brusch-Godfrey atau LM (Lagrange Multiplier) test. Berikut adalah tabel hasil Uji Autokorelasi seperti di bawah ini:

Tabel 2. Hasil Uji Autokorelasi heteroskedastisitas jika probabilitas $F$ hitung lebih besar dari taraf alpha 5\%. Nilai probabilitas $F$ hitung pada hasil estimasi di atas adalah 0,2245 , nilai tersebut lebih besar dari taraf alpha $5 \%$ sehingga model dalam penelitian ini tidak Breusch-Godfrey Serial Correlation LM Test: mengandung heteroskedastisitas.

\begin{tabular}{|c|c|c|c|}
\hline -sta & 1.005708 & Prob. $F(2,39)$ & $\begin{array}{c}\text { 3.Uji Multikotimearitas } \\
0.3751\end{array}$ \\
\hline uared & 2.256082 & Prc & II U \\
\hline
\end{tabular}

Sumber: Output Eviews 7

Pada hasil estimasi uji autokorelasi dengan menggunakan Breusch-Godfrey Serial Correlation LM Test di atas, nilai Prob. F hitung sebesar 0,3751 atau lebih besar dari tingkat alpha $5 \%(0,05)$ sehingga dapat disimpulkan bahwa model di atas tidak mengandung autokorelasi

\section{Uji Heteroskedastisitas}

Tabel 4. Hasil Uji Heteroskedastisitas Heteroskedasticity Test: Breusch-Pagan-Godfrey

F-statistic

Obs*R-squared 1.484777 5.820285

Scaled explained SS 3.449499
Coefficient Uncenterd Centered

\begin{tabular}{llll} 
Variable & Variance & VIF & VIF \\
\hline \hline C & 0.754801 & 471.9952 & NA \\
Log(KI1) & 0.015942 & 61.06332 & 1.214602 \\
KI2 & 0.006819 & 2.595405 & 1.015593 \\
Log(TKRT) & 0.004072 & 471.8149 & 1.226099 \\
TK & 0.008501 & 2.542369 & 1.326454
\end{tabular}

Sumber: Output Eviews 7

Berdasarkan tabel di atas, dapat dijelaskan bahwa untuk melihat adanya multikolinearitas dalam penelitian ini vaitu dengan melihat koefisien Variance Inflation $2245_{\text {Factor }}$ (VIF). Gangguan Prob. $F(4,41)$ multikolinearitas tidak terjadi jika VIF di bawah ${ }^{0.4856}$ Uji multikolinearitas dalam penelitian ini dapat dilihat dari hasil 
estimasi di atas. Dari hasil olahan di atas dapat dilihat bahwa nilai VIF jauh di bawah angka 10, dengan demikian dapat disimpulkan bahwa dalam model penelitian di atas tidak ada masalah multikolinearitas.

\section{KESIMPULAN DAN SARAN}

\section{Kesimpulan}

Variabel usia anak tenaga kerja wanita berpengaruh signifikan terhadap tingkat pendidikan anak tenaga kerja wanita yang bermigrasi ke luar negeri. Artinya bahwa kenaikan terhadap usia anak tenaga kerja sebesar 1 tahun maka akan meningkatkan tingkat pendidikan sebesar 9.76 kali yang merupakan (anti log dari 0.989595). Sedangkan variabel lainnya seperti jenis kelamin, pengeluaran rumah tangga dan anak berasal dari TKW Migran atau NonMigran tidak berpengaruh signifikan terhadap tingkat pendidikan anak.Artinya bahwa ketiga variabel tersebut tidak dapat menentukan kenaikan ataupun penurunan tingkat pendidikan anak tenaga kerja wanita yang bermigrasi ke luar negeri.

\section{Saran}

Berdasarkan kesimpulan penelitian, maka penulis merekomendasikan berupa saransaran sebagai berikut:

1. Dilihat dari hasil penelitian di mana dampak yang ditimbulkan dari tenaga kerja wanita yang bermigrasi ke luar negeri terhadap tingkat pendidikan anak adalah positif. Maka untuk kedepannya diharapkan kerjasama dari berbagai pihak yang terkait seperti Kementerian Tenaga Kerja dan Transmigrasi, Badan Nasional Penempatan dan Perlindungan Tenaga Kerja Indonesia (BNP2TKI) dan Kementrian Luar Negeri (Kemenlu) agar dapat mempertimbangkan kebijakankebijakan pengiriman tenaga kerja wanita informal ke luar negeri dan agar pihak-pihak tersebut meningkatkan pengawasan dan perlindungan bagi para tenaga kerja wanita untuk mengantisipasi dampak negatif seperti penipuan terhadap tenaga kerja wanita, gaji yang tidak dibayarkan atau bahkan tindakan kriminal yang dapat merugikan tenaga kerja wanita sehingga kedepannya pengiriman tenaga kerja wanita ke luar negeri dapat memberikan dampak positif bukan hanya untuk keluarga yang ditinggalkan tetapi juga berdampak positif bagi negara dimana pengiriman tenaga kerja wanita ini berpeluang untuk meningkatkan devisa negara.

2. Bagi peneliti selanjutnya, diharapkan hasil penelitian ini dapat dijadikan referensi tambahan dalam melakukan 
penelitian khususnya penelitian bermigrasi.

mengenai tenaga kerja wanita yang

\section{DAFTAR PUSTAKA}

Acosta, Pablo. (2007). Entrepreneurship, Labor Market, and International Remittances: Evidence from El Salvador. In Ozden and M. Schiff (eds). International Migration. Economic Development \& Policy (World Bank and Palgrave Macmillan: 141-159.

Badan Pusat Statistik. 2017.NTB Dalam Angka 2017. Mataram.

Badan Pusat Statistik. 2017. Kabupaten Lombok Timur Dalam Angka 2016. Lombok Timur.

Bryant,J. 2005. Children of International Migrants in Indonesia, Thailand, and the Philippines: A review of Evidence and Policies. Pdf. in www.unicef.org/irc.

Becker, S. G. 1965. A Theory of Allocation of Time.The Economics Journal. 75 (299): 493-517.

Cortes, R. 2007. Children and Women Left Behind in Labor Sending Countries: An Appraisal of Social Risks. pdf. Inwww. Childmigration. net. Com.

Gao, Yang.,et al. 2010. The Impact of Parental Migration on Health Status and Health Behaviours Among Left Behind Adolescent School Children in China.

Gujarati, N. D. 2003.Basic Econometrics. Fourth Edition. United States Military Academy. West Point.

IOM. 2004. International Migration Law: Glossary on Migration. International Organization for Migration.

------. 2005. Migration and Remittances in Moldova. Moldova: IOM.

Lu, Yao., Treiman, J. D. 2007. The Effect of Labor Migration and Remittance on Children's Education among Blacks in South Africa. California Center for Population Research. On-line Working Papper Series.

Loken, K. V. 2007. Family ncome and Children's Education: Using the Norwegian Oil Boom and A Natural Experiment. Working Papper in Economics. (3/7).

Nazir, Moh. 2005. Metode Penelitian. Ghalia Indonesia. Bogor Selatan.

Quartey, Peter. 2005. Shared Growth in Ghana: Do Migrant Remittances Have a Role?. Paper presented at the international conference Shared Growth in Africa. Cornell University. Institute of Statistical.Social and Economic Research (University of Ghana).The World Bank. Accra. July 21-22. 
Quartey, Peter, 2006. The Impact of Migrant Remittances on Household Welfare in Ghana.AERC Research Paper 158, African Economic Research Consortium, Nairobi.

Quisumbing, Agnes R., ed. 2003. Household Decisions, Gender, and Development: A Synthesis of Recent Research. Baltimore, MD: Johns Hopkins University Press for the International Food Policy Research Institute.

Quisumbing, Agnes R., and Bénédicte de la Brière. 2000. Women's Assets and Intrahousehold Allocation in Rural Bangladesh: Testing Measures of Bargaining Power. FCND Discussion Paper 86. Washington, DC: International Food Policy Research Institute, Food Consumption and Nutrition Division.

Resosudarmo, P, B,. et al. 2009. The Socioeconomic and Health Status of Rural-Urban Migrants in Indonesia. Mulyana, M. The SMERU Research Institute.

Whitehead, A., Hashim, I. 2005. Children's and Migration, Background paper for DFID Team.Pdf in. www. Childtrafficking. com.

www.BNP2TKI.go.id 